Original Article

\title{
Acute cardiovascular responses while playing virtual games simulated by Nintendo $\mathrm{Wii}^{\circledR}$
}

Gusthavo Augusto Alves Rodrigues ${ }^{1)}$, Danilo De Souza Felipe ${ }^{1)}$, Elisangela Silva ${ }^{1)}$, Wagner Zeferino De Freitas ${ }^{1)}$, Wonder Passoni Higino, PhD ${ }^{1}$, Fabiano Fernandes Da Silva 1 ,

2), Wellington Roberto Gomes De Carvalho PhD ${ }^{3)}$, Renato Aparecido de Souza, PT, PhD ${ }^{1)^{*}}$

1) Group of Studies and Research in Health Sciences (GEP-CS), Federal Institute of Education, Science and Technology of The South of Minas Gerais (IFSULDEMINAS): Rua Dinah, 75, Canaã, Muzambinho, MG, 37890-000, Brazil

2) Biomedical Engineering Institute, Camilo Castelo Branco University (UNICASTELO), Brazil

3) Department of Physical Education, Center for Biological Sciences and Health, Federal University of Maranhão (UFMA), Brazil

\begin{abstract}
Purpose] This investigation evaluated the acute cardiovascular responses that occur while playing virtual games (aerobic and balance) emulated by Nintendo Wii ${ }^{\circledR}$. [Subjects] Nineteen healthy male volunteers were recruited. [Methods] The ergospirometric variables of maximum oxygen consumption, metabolic equivalents, and heart rate were obtained during the aerobic (Obstacle Course, Hula Hoop, and Free Run) and balance (Soccer Heading, Penguin Slide, and Table Tilt) games of Wii Fit Plus ${ }^{\circledR}$ software. To access and analyze the ergospirometric information, a VO2000 analyzer was used. Normalized data (using maximum oxygen consumption and heart rate) were analyzed using repeated measures analysis of variance and Scheffe's test. [Results] Significant differences were found among the balance and aerobic games in all variables analyzed. In addition, the Wii exercises performed were considered to be of light (balance games) and moderate (aerobic games) intensity in accordance with American College Sports Medicine exercise stratification. [Conclusion] Physical activity in a virtual environment emulated by Nintendo $\mathrm{Wii}^{\circledR}$ can change acute cardiovascular responses, primarily when Wii aerobic games are performed. These results support the use of the Nintendo Wii ${ }^{\circledR}$ in physical activity programs.

Key words: Ergospirometric, Functional Exercises, Exergames
\end{abstract}

(This article was submitted May 11, 2015, and was accepted Jun. 9, 2015)

\section{INTRODUCTION}

Recently, the use of a new class of video games called exergames $(\mathrm{EXG})$ has been investigated with the premise that such games produce cardiovascular responses similar to aerobic fitness activities ${ }^{1)}$. Although acute cardiovascular responses have not yet been effectively described with the use of Nintendo Wii ${ }^{\circledR}$, the world's most popular EXG, it has been proposed that some Wii games could help meet the recommendations of the American College of Sports Medicine (ACSM) regarding the improvement and maintenance of cardiorespiratory fitness ${ }^{2,3)}$.

In older people, previous studies suggest that an EXG program may be feasible, acceptable, and beneficial for promoting balance, walking activity, memory, quality of life ${ }^{4}$, and cardiovascular fitness ${ }^{5,6}$. In overweight young adults, Wii balance board exercise can improve balance and lower

*Corresponding author. Renato Aparecido De Souza (E-mail: tatosouza2004@yahoo.com.br)

C2015 The Society of Physical Therapy Science. Published by IPEC Inc. This is an open-access article distributed under the terms of the Creative Commons Attribution Non-Commercial No Derivatives (by-ncnd) License $<$ http://creativecommons.org/licenses/by-nc-nd/3.0/>. limb muscle strength ${ }^{7)}$. Thus, new studies to examine the efficacy and sustainability of EXG for adult engagement in physical activity for health promotion, using precise equipment such as gas exchange devices to obtain cardiovascular variables, should be encouraged.

An understanding of physiologic responses during physical activity is critical for developing strategies and obtaining parameters that allow for adjustment of rehabilitation programs and guarantee the safety of patients, especially when their clinical conditions involve high risks. Therefore, this study aimed to evaluate the acute cardiovascular responses (maximum oxygen consumption $\left[\mathrm{VO}_{2}\right]$, metabolic equivalents [METs], and heart rate [HR]) that occur while playing virtual games (aerobic and balance) emulated by Nintendo $\mathrm{Wii}^{\circledR}$. From results obtained in this study, we can compare the virtual exercise intensity level with recommendations for physical activity to verify the necessary adjustments for health promotion using virtual games.

\section{SUBJECTS AND METHODS}

The subject population was a convenience sample composed of 19 healthy male volunteers recruited from the physical education faculty. Demographic data for the sample were as follows (mean \pm standard deviation [SD]): age (20 
Table 1. Percentage of maximum oxygen consumption, heart rate, and metabolic equivalents

\begin{tabular}{|c|c|c|c|}
\hline Wii games & $\% \mathrm{VO}_{2 \max }$ & $\% \mathrm{HR}_{\max }$ & METs \\
\hline Soccer heading & $14.70 \pm 3.93^{\#}$ & $42.06 \pm 4.61^{\#}$ & $2.49 \pm 0.81^{\#}$ \\
\hline Table tilt & $13.21 \pm 3.30^{\#}$ & $40.04 \pm 3.71^{\#}$ & $2.22 \pm 0.72^{\#}$ \\
\hline Penguin slide & $14.66 \pm 4.29^{\#}$ & $40.66 \pm 4.55^{\#}$ & $2.46 \pm 0.90^{\#}$ \\
\hline Obstacle course & $22.95 \pm 8.15^{\#, *}$ & $48.44 \pm 6.90^{\#, *}$ & $3.73 \pm 1.22^{\#, *}$ \\
\hline Hula hoop & $36.93 \pm 11.69^{\#, *}$ & $61.66 \pm 13.61^{\#, *}$ & $6.27 \pm 2.29^{\#, *}$ \\
\hline Free run & $47.07 \pm 14.03^{\#, *}$ & $64.35 \pm 13.70^{\#, *}$ & $8.19 \pm 3.22^{\#, *}$ \\
\hline \multicolumn{4}{|c|}{$\begin{array}{l}\text { *indicates statistical differences between aerobic games }(\mathrm{p}<0.05) \\
\#_{\text {indicates differences in aerobic versus balance games }(\mathrm{p}<0.05) \text {. }} \text {. } \\
\% \mathrm{VO}_{2 \max }: \text { Percentage of maximum oxygen consumption } \\
\% \mathrm{HR}_{\max }: \text { Percentage of maximum heart rate } \\
\text { METS: Metabolic equivalents }\end{array}$} \\
\hline
\end{tabular}

\pm 2 years); body mass $(73 \pm 8 \mathrm{~kg})$; height $(173 \pm 3 \mathrm{~cm})$; fat percentage $(16 \pm 4 \%)$; lean mass percentage $(84 \pm 5 \%)$; and $\mathrm{VO}_{2}\left(49.8 \pm 5.46 \mathrm{ml} \cdot \mathrm{kg}^{-1} \cdot \mathrm{min}^{-1}\right)$. None of the volunteers was involved in an intense aerobic training regimen nor maintained a sedentary lifestyle; all exercised at least 30 minutes three times a week. All participants read and signed an informed consent, and the study was approved by the Ethics Committee designed by the Brazilian Platform (Protocol number 428.527/20130).

The virtual reality environment was simulated by the Nintendo $\mathrm{Wii}^{\circledR}$. Input devices that allowed the user-Wii interaction were the Wii Balance Board and Sensor Bar. The Wii Balance Board has 4 pressure sensors that measure users' body weight distribution on the lower limbs and their balance. Wii Fit Plus ${ }^{\circledR}$ software, which incorporates balance, aerobic, yoga, and strengthening activities, was used. For this study, 3 aerobic games (Obstacle Course, Hula Hoop, and Free Run) and 3 balance games (Soccer Heading, Penguin Slide, and Table Tilt) were chosen.

First, the volunteers performed an incremental treadmill $\mathrm{VO}_{2 \max }$ test with gas exchange analysis according to the protocol proposed by Worley et al. ${ }^{8)}$ to obtain the maximum values for the ergospirometric variables $\mathrm{VO}_{2 \max }, \mathrm{HR}_{\text {max }}$, and $\mathrm{METs}_{\max }$. Then, 48 hours later, all Wii games were performed twice in randomized order. All Wii games were 8 min in duration with 5-minute intervals between them. All volunteers were encouraged to develop their maximum performance during the game.

During the execution of each game, ergospirometric variables were monitored continuously using a portable metabolic and gas $\left(\mathrm{O}_{2}\right.$ and $\left.\mathrm{CO}_{2}\right)$ measuring system, VO2000 (MGC Diagnostics, Saint Paul, MN, USA). The unit, including battery pack, harness, and cables, weighs $1.5 \mathrm{~kg}$ and uses the preVent ${ }^{\mathrm{TM}}$ Pneumotach to measure ventilation from expiratory flow volumes and the BreezeSuite software package for data collection and manipulation. Prior to each game, the VO2000 was calibrated according to the manufacturer's instructions. HR was measured continuously using a chest strap HR monitor (Polar S810; Polar Electro Oy, Kempele, Finland).

Average $\mathrm{VO}_{2}$ and $\mathrm{HR}$ values are presented as a percentage of the $\% \mathrm{VO}_{2 \max }$ and $\% \mathrm{HR}_{\max }$ and were stratified by the following intensity ranges $\left.{ }^{9}\right)$ : (a) very light $(<37 \%$ of
$\mathrm{VO}_{2 \max }$, or $<57 \%$ of $\mathrm{HR}_{\max }$ ); (b) light (37-45\% of $\mathrm{VO}_{2 \max }$, or $57-63 \%$ of $\mathrm{HR}_{\max }$ ); (c) moderate $\left(46-63 \%\right.$ of $\mathrm{VO}_{2 \max }$, or $64-76 \%$ of $\left.\mathrm{HR}_{\max }\right)$; (d) vigorous $\left(64-90 \%\right.$ of $\mathrm{VO}_{2 \max }$, or $77-95 \%$ of $\left.\mathrm{HR}_{\max }\right)$; and (e) near- ${ }_{\max }$ imal to ${ }_{\max }$ imal $(\geq 90 \%$ of $\mathrm{VO}_{2 \max }$, or $\geq 96 \%$ of $\mathrm{HR}_{\max }$ ).

Statistical Package for the Social Sciences (IBM Corporation SPSS, Version 20.0, Chicago, IL, USA) was used to perform the statistical analysis, with $\alpha=0.05$ set as the level of statistical significance. Comparisons were made for the $\% \mathrm{VO}_{2 \max }, \% \mathrm{HR}_{\max }$, and METs in each Wii game and in both categories (aerobic and balance) using repeated measures analysis of variance. Post hoc analyses were performed, when necessary, using Scheffe's test.

\section{RESULTS}

Table 1 illustrates the results related to $\% \mathrm{VO}_{2 \max }$, $\% \mathrm{HR}_{\max }$, and METs achieved during all Wii games. Aerobic games had higher values $(p<0.05)$ than balance games, but only the aerobic games Free Run and Hula Hoop were classified as moderate intensity. Furthermore, the aerobic games showed a statistically significant difference between each other $(p<0.05)$. No significant difference was found between balance games, and all balance games were classified as very light intensity.

\section{DISCUSSION}

The use of any tool that aims to improve cardiovascular status to minimize health problems related to physical inactivity is important to consider. Furthermore, cardiovascular monitoring is critical for understanding the physiological demands of a specific type of physical exertion. After clarification of cardiovascular demand, it is possible to develop strategies and obtain parameters to adjust rehabilitation programs, especially for individuals with high cardiovascular risk. In view of this, this study examined the acute cardiovascular responses $\left(\mathrm{VO}_{2}, \mathrm{METs}\right.$, and $\left.\mathrm{HR}\right)$ that occurred while subjects played virtual games simulated by Nintendo $\mathrm{Wii}^{\circledR}$.

Physical activity for the purpose of health promotion should be performed according to specific recommendations concerning duration, frequency, and moderate-intensity 
level ${ }^{9)}$. Usually, the ACSM categorizes moderate-intensity level using parameters related to $\mathrm{VO}_{2}$, METs, and $\mathrm{HR}$, with HR considered the most practical parameter to monitor, especially in terms of reliability, safety, and $\operatorname{cost}^{9)}$. In the present study, we observed that two aerobic games (Hula Hoop and Free Run) achieved moderate intensity, which suggests the viability of these exercises for improvement and maintenance of cardiorespiratory fitness in accordance with ACSM guidelines. Guderian et al. ${ }^{10)}$ evaluated cardiovascular and metabolic responses during performance of Wii Fit games in adults of middle age and older to determine whether virtual games would meet ACSM guidelines for health promotion. Results showed that the exercises' mean intensity level was $43.4 \pm 16.7 \%$ of reserve HR, with $3.5 \pm 0.96$ METs and energy expenditure of $116.2 \pm 40.9 \mathrm{kcal} / \mathrm{session}$, also indicating that virtual games should be considered an alternative tool for improving physical fitness and health. In addition, Douris et al. ${ }^{3)}$ compared physiological and psychological responses of 21 healthy and sedentary college students after they were subjected to 30 minutes of exercise, such as brisk walking on the treadmill, versus 30 min of Nintendo Wii Fit on Free Run mode. Although the exercise intensity level has been considered moderate in the two experimental situations, all variables showed significantly higher values in the virtual exercise performance.

Obstacle Course was the only Wii aerobic game for which $\mathrm{VO}_{2}$ and $\mathrm{HR}$ values were consistent with light exercise. This Wii aerobic game probably did not achieve moderate intensity because its operational procedure requires the subject to pass obstacles in short phases with short rests between them, which could decrease physical demands. However, the entertainment and fun promoted by this game indicates that it could be used during warm-up or cool-down periods of rehabilitation. In an attempt to characterize Wii games, Miyachi et al. ${ }^{2)}$ evaluated METs of 12 adult volunteers who performed approximately 70 Wii games. Results showed that $67 \%$ of activities were classified as light-intensity $(<3$ METs), 33\% as moderate-intensity (3-6 METs), and none as vigorous-intensity ( $>6$ METs).

Among the balance games Soccer Heading, Penguin Slide, and Table Tilt, all were considered as light-intensity exercises. Wii balance games impose challenging tasks for maintenance of postural balance and are considered as having a high level of enjoyment, satisfaction, and interaction of participants in the Wii virtual environment ${ }^{11)}$. However, virtual activity alone should not replace a goal-oriented program. Virtual games should be seen as an auxiliary tool to help reduce monotony and increase entertainment and adherence to physical activity, always with the guidance of a professional ${ }^{12)}$.

In summary, physical activity in a virtual environment emulated by Nintendo Wii ${ }^{\circledR}$ can change acute cardiovascular responses, primarily when Wii-aerobic games are performed. These results support the use of the Nintendo $\mathrm{Wii}^{\circledR}$ in physical activity programs.

\section{ACKNOWLEDGEMENTS}

F.F. Silva thanks Coordination for the Improvement of Higher Education Personnel (CAPES) for doctoral scholarship. R.A. Souza thanks Fundaçao de Amparo da Pesquisa do Estado de Minas Gerais (FAPE-MIG) for research grant support (grant. APQ-02660-12). W.P. Higino thanks Instituto Federal de Educação, Ciência e Tecnologia do Sul de Minas Gerais (IFSULDEMINAS), for publication financial support.

\section{REFERENCES}

1) Naugle KE, Naugle KM, Wikstrom EA: Cardiovascular and affective outcomes of active gaming: using the nintendo wii as a cardiovascular training tool. J Strength Cond Res, 2014, 28: 443-451. [Medline] [CrossRef]

2) Miyachi M, Yamamoto K, Ohkawara K, et al.: METs in adults while playing active video games: a metabolic chamber study. Med Sci Sports Exerc, 2010, 42: 1149-1153. [Medline]

3) Douris PC, McDonald B, Vespi F, et al.: Comparison between Nintendo Wii Fit aerobics and traditional aerobic exercise in sedentary young adults. J Strength Cond Res, 2012, 26: 1052-1057. [Medline] [CrossRef]

4) Yoon JE, Lee SM, Lim HS, et al.: The effects of cognitive activity combined with active extremity exercise on balance, walking activity, memory level and quality of life of an older adult sample with dementia. J Phys Ther Sci, 2013, 25: 1601-1604. [Medline] [CrossRef]

5) Serber E, Ciccolo J, Palmer K, et al.: The feasibility of exercise videogames for cardiovascular risk reduction among adults: a pilot for "Wii Heart Fitness". J Sports Med Phys Fitness, 2015, [Epub ahead of print]. [Medline]

6) Fachko MJ, Xiao C, Bowles KH, et al.: Cardiovascular effects and enjoyment of exercise gaming in older adults. J Gerontol Nurs, 2013, 39: 43-54. [Medline] [CrossRef]

7) Siriphorn A, Chamonchant D: Wii balance board exercise improves balance and lower limb muscle strength of overweight young adults. J Phys Ther Sci, 2015, 27: 41-46. [Medline] [CrossRef]

8) Worley JR, Rogers SN, Kraemer RR: Metabolic responses to Wii Fit ${ }^{\mathrm{TM}}$ video games at different game levels. J Strength Cond Res, 2011, 25: 689693. [Medline] [CrossRef]

9) Garber CE, Blissmer B, Deschenes MR, et al. American College of Sports Medicine: American College of Sports Medicine position stand. Quantity and quality of exercise for developing and maintaining cardiorespiratory, musculoskeletal, and neuromotor fitness in apparently healthy adults: guidance for prescribing exercise. Med Sci Sports Exerc, 2011, 43: 13341359. [Medline] [CrossRef]

10) Guderian B, Borreson LA, Sletten LE, et al.: The cardiovascular and metabolic responses to Wii Fit video game playing in middle-aged and older adults. J Sports Med Phys Fitness, 2010, 50: 436-442. [Medline]

11) Lyons EJ, Tate DF, Komoski SE, et al.: Novel approaches to obesity prevention: effects of game enjoyment and game type on energy expenditure in active video games. J Diabetes Sci Tech, 2012, 6: 839-848. [Medline] [CrossRef]

12) Souza RA, Cruz LG, Carvalho PS, et al.: Acute cardiovascular responses in a virtual environment simulated by Nintendo Wii. Rev Bras Cineantropom Desempenho Hum, 2013, 15: 60-70. [CrossRef] 